\title{
Clinical Use of FSH in Male Infertility
}

\author{
Hermann M. Behre* \\ Center for Reproductive Medicine and Andrology, University Hospital Halle, Martin Luther University Halle-Wittenberg, Halle,
} Germany

The established clinical indication for FSH use in male infertility is the treatment of patients with hypogonadotropic hypogonadism for stimulation of spermatogenesis that allows the induction of a clinical pregnancy in the female partner and finally the birth of a healthy child. Several clinical studies with urinary, purified, and recombinant FSH preparations in combination with hCG have demonstrated the high treatment efficacy regarding these clinical endpoints. Shortcomings of this hormone therapy are the long duration of treatment, sometimes longer than 2 years, and the inconvenience of injections every second or third day. However, improvements of therapy might be expected with new hormonal treatment options already available for infertility treatment in the female.

OPEN ACCESS

Edited by:

Manuela Simoni,

University of Modena and Reggio

Emilia, Italy

Reviewed by:

Alberto Ferlin,

University of Brescia, Italy

Sandro C. Esteves,

Androfert, Andrology and Human

Reproduction Clinic, Brazi

*Correspondence:

Hermann M. Behre

Hermann.Behre@medizin.uni-halle.de

Specialty section: This article was submitted to

Reproduction,

a section of the journal Frontiers in Endocrinology

Received: 18 March 2019 Accepted: 02 May 2019 Published: 24 May 2019

Citation: Behre HM (2019) Clinical Use of FSH in Male Infertility.

Front. Endocrinol. 10:322. doi: 10.3389/fendo.2019.00322
FSH use for treatment of patients with normogonadotropic idiopathic infertility and oligozoospermia is still considered experimental in most countries. Recent meta-analyses have shown that FSH can significantly increase pregnancy rates in the female partners of these patients, but the effect-size is relatively low. Therefore, predictive factors for treatment success have to be identified, including FSH pharmacogenetics, to select the right normogonadotropic patients with idiopathic infertility for FSH therapy.

Keywords: FSH, hMG, hCG, male infertiltiy, hypogonadotropic hypogonadism, idiopathic male infertility

\section{INTRODUCTION}

In male infertility, the indication for treatment with follicle stimulating hormone (FSH) is the induction and maintenance of spermatogenesis in patients with hypogonadotropic hypogonadism (1). As these patients are normally azoospermic without gonadotropin stimulation and during testosterone therapy, the presence of sufficiently high numbers of progressively motile and normally formed sperm in the ejaculate during exogenous gonadotropin therapy might result in the desired clinical pregnancy for many infertile couples. On an experimental basis, and in some places already in clinical routine, FSH preparations are also used for treatment of normogonadotropic infertile men with idiopathic impairment of spermatogenesis $(2,3)$.

The primary goal of FSH therapy in the hypogonadotropic or normogonadotropic patients is not the stimulation of testicular growth or spermatogenesis per se, but the induction of a pregnancy in the female partner of the infertile couple, and finally the live birth of a healthy child. This review summarizes the effects of FSH treatment on this primary clinical outcome in these two patient groups with male infertility. The administration of FSH to children or during adolescence is not the topic of this review. 


\section{FSH THERAPY FOR MALE INFERTILITY IN PATIENTS WITH HYPOGONADOTROPIC HYPOGONADISM}

In patients with hypogonadotropic hypogonadism, male infertility is due to the lack of stimulation of spermatogenesis by the gonadotropins FSH and luteinizing hormone (LH). In so-called idiopathic/isolated/congenital hypogonadotropic hypogonadism ( $\mathrm{IHH}$ or $\mathrm{CHH}$ ) and Kallmann syndrome, the core pathophysiological feature is the disturbed hypothalamic synthesis or secretion of gonadotropin-releasing hormone (GnRH) (4). This leads to diminished or absent LH and FSH synthesis or secretion by the unstimulated pituitary gland and finally to endocrine hypogonadism with low testosterone serum levels and infertility with azoospermia or severe oligozoospermia as the respective laboratory markers. Various other diseases including secondary GnRH deficiency lead to the same pathophysiology (4).

Other causes for hypogonadotropic hypogonadism are pituitary insufficiency due to tumors (especially makroprolactinomas), metastases of the pituitary and the hypophyseal stalk, post-operative states, radiotherapy of the pituitary region, traumata, infections, hemochromatosis, vascular disorders, and others (4). Hypogonadotropic hypogonadism is caused by the insufficiency of the pituitary gland to secret significant levels of LH and FSH. The clinical picture in these patients is additionally influenced by possible disturbances of the other pituitary hormones.

The therapy of choice in patients with hypogonadotropic hypogonadism due to various pathophysiologic causes as mentioned above is-for most of the time of the life-spanthe exogenous substitution of testosterone to maintain all androgen-dependent functions. This therapy is well established over decades, relatively convenient for the male patients and comparably inexpensive (5).

In case the patients develop the wish to have children with their female partner, the testosterone substitution therapy is no longer sufficient and has to be interrupted. The patients should then be treated with FSH preparations and in addition with a pharmacological preparation to stimulate intratesticular testosterone production by the Leydig cells. As no LH preparation is currently approved for male hypogonadotropic hypogonadism, patients are usually treated with human chorionic gonadotropin (hCG) preparations with similar, but not identical bioactivity (6). hCG has a longer elimination half-life than LH and patients can be treated effectively by two injections per week (4).

In patients with hypogonadotropic hypogonadism caused by hypothalamic disorders, exogenous pulsatile $\mathrm{GnRH}$ can also be used for treatment, as this will stimulate the FSH and LH secretion from the pituitary gland $(4,7)$. Because of the complex and time-consuming pulsatile therapy, today only few patients with hypogonadotropic hypogonadism are treated with pulsatile GnRH. Pulsatile GnRH therapy seems to have no proven advantage over FSH plus hCG therapy in patients with hypothalamic hypogonadotropic hypogonadism. However, the lack of sufficient well-designed, randomized prospective studies does not allow firm conclusions on the best therapy for infertility in these patients $(8,9)$.

\section{Early Experience With $\mathrm{hMG}$ in Combination With hCG Therapy}

FSH has been used successfully for infertility treatment of patients with hypogonadotropic hypogonadism for more than 50 years, initially with urinary menopausal gonadotropins having FSH activity. It is worth reading the initial reports of FSH therapy in hypogonadotropic patients. MacLeod and coworkers reported on the successful therapy with urinary menopausal gonadotropins of a 37-year-old patient who underwent complete hypophysectomy in $1963(10,11)$. The patient had provided a semen sample 1 day before the hypophysectomy that showed 576 million sperm per ejaculate and quite good sperm motility and morphology. After surgery, the ejaculate quality decreased significantly and, following several weeks after hypophysectomy, the patient was unable to provide semen samples any more. Approximately 14 weeks after hypophysectomy, a bilateral testicular biopsy was performed which showed involution of spermatogenesis to the level of spermatogonia and only few areas with primary spermatocytes. One day after the first testicular biopsy, treatment with hMG (human menopausal gonadotropin originating from human urine with mainly FSH and some LH activity) was initiated in the patient, at a dose of approximately 206 I.U. per day.

After 64 days of menopausal gonadotropin treatment, another testicular biopsy only of the right testis revealed stimulated spermatogenesis, showing all stages of spermatogenesis including late elongated testicular spermatids. However, the restoration of spermatogenesis appeared only qualitatively normal, not quantitatively. As a patient was still unable to produce an ejaculate probably due to the insufficient low LH activity in the hMG preparation and therefore low testosterone serum levels, hCG therapy with 4000 I.U. on alternate days was added to stimulate testosterone production by the Leydig cells. At the same time the hMG dose of 206 I.U. was given no longer daily, but only every second day (alternating with hCG injections). With the combined therapy of hMG and hCG the patient regained the ability to produce an ejaculate that showed a total sperm count of several million with progressive sperm motility and normal sperm morphology, that were still decreased compared to the levels analyzed before hypophysectomy (11). Later the patient decided not to continue with hMG therapy and, unfortunately, no fertility data are available. However, this early comprehensive case report demonstrated clearly the principle of FSH therapy in combination with hCG for stimulation of spermatogenesis in patients with hypogonadotropic hypogonadism.

\section{Clinical Studies With hMG in Combination With hCG Therapy}

Since then, several patients with hypogonadotropic hypogonadism were treated successfully with hMG plus hCG, for stimulation of spermatogenesis and achieving the desired pregnancy in the female partner. One of the most comprehensive studies on the treatment efficacy in patients with 
different etiologies for hypogonadotropic hypogonadism was published by Büchter et al. more than 20 years ago (8). This study might be regarded as one reference study for hMG treatment of these patients, as at that time hMG has been replaced more and more by highly purified or recombinant FSH preparations in the andrology clinic $(12,13)$. In this study by Büchter and colleagues, 21 patients with hypogonadotropic hypogonadism due to pituitary disorders were treated with hMG plus hCG. As in some of these patients more than one treatment course was performed, 30 treatment courses could be included in the study analysis. Another 18 patients with hypogonadotropic hypogonadism due to hypothalamic disorders such as Kallmann syndrome or congenital hypogonadotropic hypogonadism were treated with hMG plus hCG (18 cases, 20 treatment courses). Altogether, 31 of the 50 treatment courses with hMG plus hCG were initiated for the induction of pregnancy in the female partner and 19 of 50 courses only for the induction of spermatogenesis.

In all of the 30 treatment courses (100\%) in patients with a pituitary disorder, spermatogenesis was stimulated from azoospermia to the presence of sperm in the ejaculate. In patients with a hypothalamic disorder, gonadotropin therapy induced spermatogenesis in 18 of 20 treatment courses (90\%). The duration of therapy until the first detection of sperm in the ejaculate was quite variable. In the patients with a pituitary disorder, the average treatment time was 4 months (range 216 months). In the patients with a hypothalamic disorder, the average treatment duration was 6 months (1-18 months). The duration of time until induction of pregnancy of the female partner in patients with pituitary disorders was 10 months (246 months), and 8 months (1-15 months) in the patients with hypothalamic disorders. For this review article, the information on pregnancies was included that was added in proof of the publication by Büchter et al. (8). An additional pregnancy in the female partner occurred after gonadotropin treatment of one patient with pituitary disorder for 42 months as well as one patient with hypothalamic disorder treated for 48 months. Including these data, hMG plus hCG therapy in patients with a pituitary disorder resulted in 18 pregnancies in 21 treatment courses $(86 \%)$ and 6 pregnancies in 10 treatment courses $(60 \%)$ in patients with a hypothalamic disorder (8). Compared to other current treatments of infertility including application of assisted reproductive techniques (ART), this "causal" therapy of male infertility in patients with hypogonadotropic hypogonadism proved to be highly effective (14).

\section{Factors Influencing the Efficacy of Treatment}

While hMG plus hCG therapy of infertile patients with hypogonadotropic hypogonadism appears to be quite successful regarding stimulation of spermatogenesis and finally clinical pregnancy induction in the female partner, the treatment might last quite long. Patients have to be informed that hormone therapy might last for several months and even years before the desired pregnancy can be achieved. Therefore, it is relevant to identify predictive factors influencing treatment efficacy (Box 1).
In an recent study on 51 adult patients with hypogonadotropic hypogonadism who had undergone one treatment cycle with FSH (urinary or recombinant FSH) plus hCG, those patients who had hypogonadotropic hypogonadism acquired after puberty or had a pubertal arrest showed significantly better treatment outcome (15). These patients achieved higher final bilateral testicular volume and higher final sperm concentrations compared to patients with hypogonadotropic hypogonadism manifesting before the normal onset of puberty. Most relevant, the pregnancy rate of $62 \%$ was higher in patients with post-pubertally acquired hypogonadotropic hypogonadism compared with those patients with pre-pubertally acquired hypogonadism (42\%). In addition, a conception in the female partners of patients with postpubertally acquired hypogonadotropic hypogonadism occurred significantly earlier $(20.3 \pm 11.5$ months $)$ than in the female partners of patients with pre-pubertally acquired hypogonadism (43.1 \pm 43.8 months).

The therapeutic success was also higher in patients without previously undescended testes, in patients with higher baseline testicular volume and in patients with higher baseline inhibin B serum concentrations (15). The identification of these predictive factors is in line with various clinical studies by other study groups (16-21).

\section{Clinical Studies With Recombinant or Urinary FSH in Combination With hCG Therapy}

No adequate large, randomized controlled trials (RCTs) have been performed to compare efficacy of recombinant or highly purified FSH with the urinary hMG preparations in malesquite in contrast to the application of FSH preparations in females for ART. From the available information, it seems that the efficacy of the various FSH preparations in male patients with hypogonadotropic hypogonadism is quite comparable, regarding stimulation of spermatogenesis and inducing the desired pregnancy in the female partner $(13,18,20-25)$. Today, in Germany only recombinant FSH and no longer urinary FSH preparations are approved for this therapy in male patients.

\section{Common Dosing Schemes}

One of the most common dosing schemes of gonadotropins in male hypogonadotropic hypogonadism is the administration of 150-225 I.U. FSH two or three times a week in combination with 1000-2500 I.U. of hCG two times per week (4). Several

Box 1 | Predictive factors for treatment success.

Clinical factors at initiation of FSH plus hCG therapy of adult male patients with hypogonadotropic hypogonadism predicting successful infertility treatment (15)

- History of normal puberty or pubertal arrest

- No history of cryptorchidism

- Higher baseline testicular volume

- Higher baseline serum levels of inhibin B 
physicians start treatment with hCG alone for e.g., 3 months, as some patients-maybe those with some residual FSH activityachieve stimulation of spermatogenesis by hCG alone $(13,20$, 25, 26). However, the sperm concentrations seen after hCG therapy alone appear to be lower than those with the combined treatment with FSH plus hCG (27). Therefore, FSH should also be added in these hCG-treated patients at some timepoint to achieve best treatment outcome. In addition, it has been shown that induction of spermatogenesis achieved by FSH plus hCG treatment in hypogonadotropic hypogonadism can be maintained qualitatively, but not quantitatively in most of the patients with hCG alone (28). On this line, a sequential therapy with 3 months treatment with FSH plus hCG alternated by hCG therapy alone for another 3 months has been proposed to reduce the relatively high costs of gonadotropin therapy (29). However, it is not known if this dosing regimen has the same high efficacy on the primary outcome clinical pregnancy rate.

The dose and injection interval of FSH might be adapted in individual hypogonadotropic patients to achieve optimal treatment outcome. The efficacy can be monitored by the increase of testicular volume, the stimulation of spermatogenesis, the serum levels of FSH achieved, the serum levels of testosterone achieved, and other factors. Unfortunately, large randomized comparative studies with different FSH preparations, different doses and different injection intervals are missing $(13,24)$. A retrospective study suggested that lower weekly FSH doses are sufficient to stimulate spermatogenesis and allow induction of the desired pregnancy in the female partner (24). Others have argued that the hCG dose in combination with FSH might be too high for optimal treatment effects (30). As the current FSH plus hCG dosing schemes have still the drawback of a quite long treatment duration before the desired pregnancy is achieved, it still seems rewarding to test different FSH and hCG preparations and dosing regimens by proper designed randomized controlled clinical trials to improve treatment outcome of gonadotropin therapy in male hypogonadotropic hypogonadism.

\section{FSH in Combination With Recombinant hCG or LH}

In Germany, recombinant hCG and $\mathrm{LH}$ preparation are approved for reproductive hormone therapy in women. In men, so far no adequate studies have been published comparing these preparations with urinary hCG. A combination of recombinant FSH with recombinant $\mathrm{LH}$ or hCG in one injection pen would allow easier self-administration, more fine tuning of individual therapy, higher compliance and maybe higher treatment efficacy. In addition, it could be speculated that LH instead of hCG therapy in combination with FSH could lead to much better clinical efficacy regarding stimulation of spermatogenesis and pregnancy rate in male hypogonadotropic hypogonadism $(6,30)$. So far injection pens with recombinant $\mathrm{LH}$ are only approved for treatment of females and it is about time to provide these options also to male hypogonadotropic patients. The pharmaceutical companies should be encouraged to initiate the respective clinical studies.

\section{Long-Acting FSH Preparations}

Another option for treatment improvement would be to use long-acting FSH analogs that are already used successfully in the fertility care of women. In a recent phase III multicenter clinical trial of corifollitropin alfa in azoospermic men with hypogonadotropic hypogonadism, it was demonstrated that administration of $150 \mu \mathrm{g}$ of a long-acting FSH preparation given every second week leads to significant increase of testicular volume and induction of spermatogenesis, comparable to the effects seen with short-acting recombinant FSH preparations (25).

\section{FSH THERAPY IN NORMOGONADOTROPIC MEN WITH IDIOPATHIC INFERTILITY}

\section{Early Non-randomized Studies}

As FSH therapy proved to be quite successful regarding stimulation of spermatogenesis of patients with hypogonadotropic hypogonadism and pregnancy rate in their female partners, it was tested whether this therapy can also be applied successfully in male patients with normogonadotropic idiopathic infertility. Early uncontrolled studies in these patients with hMG plus hCG therapy over a treatment period of 3 months demonstrated an increase of total sperm number in the ejaculate and also pregnancy rate in the female partners (31). The increase in pregnancy rate was especially evident in the so-called responders who were defined by an increase of sperm output of at least 25 million per ejaculate (31).

\section{Placebo-Controlled Randomized Studies}

However, it could not be excluded that the positive FSH effects in the normogonadotropic patients in uncontrolled trials were due to the well-known regression-to-the-mean phenomenon. The efficacy of hMG plus hCG treatment for 13 weeks in normogonadotropic patients with oligozoospermia was consequently revisited in a randomized, placebo-controlled, double-blind clinical study. The positive effects seen in the uncontrolled trials could not be confirmed by this randomized study. The effects on the classical variables of ejaculate analysis according to WHO were similar in the verum and placebo group (32). However, two of 19 patients treated with hMG plus hCG achieved a pregnancy in the female partner within 2 months after cessation of treatment while no pregnancy was induced by the 20 patients treated with placebo.

Because of the low number of patients included, this randomized controlled study did not have enough power to allow conclusions about pregnancy rates. In addition, the conventional ejaculate analysis might not detect all positive effects that are relevant for fertility. FSH therapy has clear positive effects on sperm DNA condensation and fragmentation that seems to be quite relevant for fertility $(2,33-37)$. These aspects might be overlooked by the standard procedures for semen analysis currently recommended by WHO (38). 
TABLE 1 | Main results of two recent meta-analyses on pregnancy rates after FSH treatment of men with idiopathic infertility.

\begin{tabular}{|c|c|c|c|c|}
\hline Inclusion criterion & $\begin{array}{l}\text { Number of patients treated } \\
\text { with } \mathrm{FSH}^{\star}\end{array}$ & $\begin{array}{l}\text { Number of patients treated } \\
\text { with placebo or untreated }\end{array}$ & $\begin{array}{l}\text { Odds ratio [95\% confidence interval] } \\
\text { for spontaneous pregnancy rate }{ }^{\#}\end{array}$ & $\begin{array}{l}\text { Reference of the } \\
\text { meta-analysis }\end{array}$ \\
\hline $\begin{array}{l}\text { Randomized controlled } \\
\text { clinical trials }\end{array}$ & 201 & 211 & 4.94 [2.13-11.44] & (39) \\
\hline Controlled clinical trials & 384 & 308 & 4.50 [2.17-9.33] & $(40)$ \\
\hline
\end{tabular}

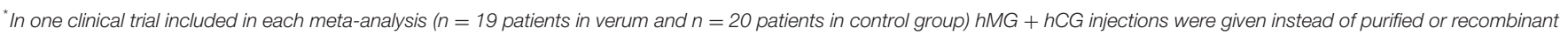
FSH. "Test for overall effect: $Z=3.72(P=0.00020)(39)$ and $Z=4.04(P<0.0001)(40)$.

\section{Meta-Analysis of Controlled Studies}

As there are no published controlled studies with sufficiently high numbers of participants yet, the effects on the pregnancy rate can only be assessed by meta-analysis. In 2013, an updated Cochrane review summarized the scientific evidence on efficacy of gonadotropin therapy in idiopathic male factor infertility to increase clinical pregnancy rate in the female partner (Table 1) (39). In this review, only RCTs with FSH/hMG alone or in combination with hCG for patients with idiopathic male factor infertility were considered that had a control group with placebo or no treatment. Finally, six RCTs were included in the analysis. The spontaneous pregnancy rate resulting from natural intercourse of $16 \%$ in the female partners of patients receiving gonadotropin treatment turned out to be significantly higher than the spontaneous pregnancy rate of $7 \%$ in the partners of men receiving placebo or no treatment (Peto odds ratio [OR] 4.94, 95\% CI 2.13-11.44; 5 clinical studies; 412 participants; moderatequality evidence). No difference was seen for pregnancy rates between the verum and control groups after additional treatment with intracytoplasmic sperm injection (ICSI) or intrauterine insemination, but the number of included patients was too low to allow final conclusions.

Recently, another comprehensive meta-analysis (Table 1) on clinical pregnancy rate as the main outcome variable was performed by Santi et al. including all controlled clinical trials on FSH administration (including one small study with hMG plus hCG) to male partners with idiopathic infertility (40). Randomization was not an inclusion criterion for this analysis. Altogether, 15 controlled clinical trials were included with 614 men treated with FSH and 661 patients with placebo or untreated patients. Nine of the 15 studies reported on spontaneous pregnancy rate (384 FSH-treated patients, 308 control patients). The spontaneous pregnancy rate in these nine studies was significantly higher in patients treated with FSH compared to controls (OR 4.50, 95\% CI 2.17-9.33). Eight studies evaluated pregnancy rate after FSH therapy and application of additional ART (322 FSH-treated patients, 275 controls). The ART pregnancy rate in this meta-analysis turned out to be significantly higher in the female partners of male patients with FSH treatment compared to controls (OR 1.60, 95\% CI 1.08-2.37).

\section{Effect Size of FSH Therapy on Pregnancy Rate}

Although these meta-analyses have demonstrated that FSH therapy in idiopathic normogonadotropic male infertility can increase clinical pregnancies in the female partners, the effect size is still relatively low. It has been calculated that 10 patients have to be treated with FSH to achieve one spontaneous pregnancy (40). Eighteen patients have to be treated with FSH to achieve one additional pregnancy after ART (40). As FSH preparations are quite expensive and many physicians involved in infertility treatment consider this effect not high enough, FSH treatment in idiopathic male infertility is so far not part of the routine treatment regime and not covered by insurance companies in many countries (3).

\section{Selecting the Right Normogonadotropic Patient for FSH Therapy}

To overcome these shortcomings, it is mandatory to select the right patients for FSH therapy. The evidence on FSH therapy in normogonadotropic patients is so far restricted to idiopathic infertility, which means that no identifiable, generally accepted cause for male infertility could be detected. Therefore, all male patients have to have a proper diagnostic andrological work-up before initiating any FSH therapy, and also the female partner needs to have a proper diagnostic gynecological work-up! Normogonadotropic male patients with identifiable and possibly treatable causes for male infertility (e.g., obstruction) should not be treated with FSH. Obviously, male patients with elevated bioactive FSH serum levels should not receive FSH therapy. It has been suggested not to provide FSH treatment to infertile patients with hypospermatogenesis associated with maturational disturbances at the spermatid level (2).

In addition to these factors, FSH therapy in normozoospermic infertile patients might be improved by optimizing the FSH dose, injection interval and especially treatment duration (1). In a recent prospective, double-blind, placebo-controlled clinical study in China including 354 patients with idiopathic oligozoospermia, the best results were seen in patients treated with the highest FSH dose of 300 I.U. every second day and for the longest treatment duration (maximal treatment duration in this study was 5 months) (41). Using the knowledge from the gonadotropin therapy in hypogonadotropic patients, it could be speculated that longer treatment of normogonadotropic patients would also improve pregnancy rates in the female partner (8).

One other promising approach to improve treatment outcome might be the application of FSH pharmacogenetics. Single nucleic polymorphism (SNP) p.N680S in exon 10 of the FSH receptor gene $(F S H R)$ has been shown to influence the ovarian response 
during controlled ovarian stimulation (42). Therefore, it was logical to test the effect of p.N680S also regarding FSH therapy for normogonadotropic patients with idiopathic infertility (34). In this study, the primary outcome variable was DNA fragmentation index (DFI) of sperm in the ejaculate $(36,37)$. It could be shown that total DFI decreased significantly from baseline to the end of the study - a surrogate effect indicating improved fertility-in male patients with the p.N680S homozygous $\mathrm{N}$ polymorphism, but not in the patients with p.N680S homozygous $\mathrm{S}$ polymorphism of the FSH receptor. These findings indicate that a selection of the right normogonadotropic patients for FSH therapy might be possible, and probably different treatment regimens could be used for different patients groups.

Several pharmacogenetic studies have been performed in normogonadotropic men over the last years that tested SNPs of the FSH beta subunit gene $(F S H B)$, SNPs of the FSHR, or combinations thereof $(34,35,43,44)$. These trials have been reviewed comprehensibly by Schubert and co-workers in this Research Topic of Frontiers in Endocrinology (45). Unfortunately, these clinical trials come to quite divergent study results, probably due to study design, inclusion criteria, and as one of the main factors FSH doses and injection intervals. However, only large, placebo-controlled, randomized multicentre studies with pregnancy rate-and not any surrogate marker-as the primary outcome variable will finally allow a conclusion on the value of FSH pharmacogenetics to select the right normogonadotropic patients with idiopathic infertility for FSH therapy.

\section{FSH Therapy in Patients With Failed TESE}

FSH therapy is currently suggested by different clinicians for patients with idiopathic azoospermia after failed testicular sperm extraction (TESE) (46-48). So far, these studies are case reports or have low patient numbers and do not include a randomized

\section{REFERENCES}

1. Oduwole OO, Peltoketo H, Huhtaniemi IT. Role of follicle-stimulating hormone in spermatogenesis. Front Endocrinol. (2018) 9:763. doi: $10.3389 /$ fendo. 2018.00763

2. Barbonetti A, Calogero AE, Balercia G, Garolla A, Krausz C, La Vignera S, et al. The use of follicle stimulating hormone (FSH) for the treatment of the infertile man: position statement from the Italian Society of Andrology and Sexual Medicine (SIAMS). J Endocrinol Invest. (2018) 41:1107-22. doi: 10.1007/s40618-018-0843-y

3. Colpi GM, Francavilla S, Haidl G, Link K, Behre HM, Goulis DG, et al. European academy of andrology guideline management of oligo-asthenoteratozoospermia. Andrology. (2018) 6:513-24. doi: 10.1111/andr.12502

4. Behre HM, Nieschlag E, Partsch C-J, Wieacker P, Simoni M. Diseases of the hypothalamus and the pituitary gland. In: Nieschlag E, Behre HM, Nieschlag S, editors. Andrology. Male Reproductive Health and Dysfunction. 3rd ed. Berlin: Springer (2010). p. 169-92.

5. Nieschlag E, Behre HM. Testosterone therapy. In: Nieschlag E, Behre HM, Nieschlag S, editors. Andrology. Male Reproductive Health and Dysfunction. 3rd ed. Berlin: Springer (2010). p. 437-55.

6. Casarini L, Lispi M, Longobardi S, Milosa F, La Marca A, Tagliasacchi D, et al. LH and hCG action on the same receptor results in quantitatively and qualitatively different intracellular signalling. PLoS ONE. (2012) 7:e46682. doi: 10.1371/journal.pone.0046682 control group. Therefore, no firm conclusion on the efficacy of FSH therapy in these patients with idiopathic azoospermia is possible, yet.

\section{PERSPECTIVES}

Although ART treatment is quite effective for infertile couples regarding the desired clinical pregnancy and the birth of a healthy child, there is a growing demand from patients and health authorities to apply effective causal therapies for the infertile male whenever possible and meaningful. Therefore, a systematic andrological examination of the male partner of the infertile couple should always be performed, even when some gynecological reasons for infertility have already been identified. In Germany, the thorough andrological workup is now mandatory before any ART therapy can be initiated (49).

Hypogonadotropic hypogonadism is a good example how causal hormone therapy of male infertility can be applied with high clinical efficacy regarding induction of pregnancy in the female partner. It remains to be seen if FSH therapy will also be useful and generally accepted for treatment of male infertility in normogonadotropic patients with idiopathic impairment of spermatogenesis.

Without question, more well-designed, prospective randomized studies are needed to identify the best $\mathrm{FSH}$ treatment for the infertile male patient. All relevant players in the healthcare system should be stimulated to provide the respective resources for optimizing treatment outcome of male infertility-in the male!

\section{AUTHOR CONTRIBUTIONS}

All work for this article was done by $\mathrm{HB}$.

7. Young J, Xu C, Papadakis GE, Acierno JS, Maione L, Hietamaki J, et al. Clinical management of congenital hypogonadotropic hypogonadism. Endocr Rev. (2019) 40:669-710. doi: 10.1210/er.2018-00116

8. Büchter D, Behre HM, Kliesch S, Nieschlag E. Pulsatile GnRH or human chorionic gonadotropin/human menopausal gonadotropin as effective treatment for men with hypogonadotropic hypogonadism: a review of 42 cases. Eur J Endocrinol. (1998) 139:298-303. doi: 10.1530/eje.0.1 390298

9. Mao JF, Liu ZX, Nie M, Wang X, Xu HL, Huang BK, et al. Pulsatile gonadotropin-releasing hormone therapy is associated with earlier spermatogenesis compared to combined gonadotropin therapy in patients with congenital hypogonadotropic hypogonadism. Asian J Androl. (2017) 19:680-5. doi: 10.4103/1008-682X.193568

10. Macleod J, Pazianos A, Ray BS. Restoration of human spermatogenesis by menopausal gonadotrophins. Lancet. (1964) 1:1196-7. doi: 10.1016/S0140-6736(64)91212-7

11. MacLeod J, Pazianos A, Ray B. The restoration of human spermatogenesis and of the reproductive tract with urinary gonadotropins following hypophysectomy. Fertil Steril. (1966) 17:7-23. doi: 10.1016/S0015-0282(16)35821-6

12. Kliesch S, Behre HM, Nieschlag E. Recombinant human folliclestimulating hormone and human chorionic gonadotropin for induction of spermatogenesis in a hypogonadotropic male. Fertil Steril. (1995) 63:1326-8. doi: 10.1016/S0015-0282(16)57619-5 
13. Bouloux PM, Nieschlag E, Burger HG, Skakkebaek NE, Wu FC, Handelsman DJ, et al. Induction of spermatogenesis by recombinant follicle-stimulating hormone (puregon) in hypogonadotropic azoospermic men who failed to respond to human chorionic gonadotropin alone. J Androl. (2003) 24:604-11. doi: 10.1002/j.1939-4640.2003.tb02712.x

14. Blumenauer V, Czeromin U, Fehr D, Fiedler K, Gnoth C, Krüssel JS, et al. D.I.R annual 2017 - the German IVF-registry. J Reproduktionsmed Endrokrinol. (2018) 15:217-50.

15. Rohayem J, Sinthofen N, Nieschlag E, Kliesch S, Zitzmann M. Causes of hypogonadotropic hypogonadism predict response to gonadotropin substitution in adults. Andrology. (2016) 4:87-94. doi: 10.1111/andr.12128

16. Burris AS, Rodbard HW, Winters SJ, Sherins RJ. Gonadotropin therapy in men with isolated hypogonadotropic hypogonadism: the response to human chorionic gonadotropin is predicted by initial testicular size. J Clin Endocrinol Metab. (1988) 66:1144-51. doi: 10.1210/jcem-66-6-1144

17. Miyagawa Y, Tsujimura A, Matsumiya K, Takao T, Tohda A, Koga M, et al. Outcome of gonadotropin therapy for male hypogonadotropic hypogonadism at university affiliated male infertility centers: a 30-year retrospective study. $J$ Urol. (2005) 173:2072-5. doi: 10.1097/01.ju.0000158133.09197.f4

18. Liu PY, Baker HW, Jayadev V, Zacharin M, Conway AJ, Handelsman DJ. Induction of spermatogenesis and fertility during gonadotropin treatment of gonadotropin-deficient infertile men: predictors of fertility outcome. J Clin Endocrinol Metab. (2009) 94:801-8. doi: 10.1210/jc.2008-1648

19. Warne DW, Decosterd G, Okada H, Yano Y, Koide N, Howles CM. A combined analysis of data to identify predictive factors for spermatogenesis in men with hypogonadotropic hypogonadism treated with recombinant human follicle-stimulating hormone and human chorionic gonadotropin. Fertil Steril. (2009) 92:594-604. doi: 10.1016/j.fertnstert.2008.07.1720

20. Dwyer AA, Raivio T, Pitteloud N. Gonadotrophin replacement for induction of fertility in hypogonadal men. Best Pract Res Clin Endocrinol Metab. (2015) 29:91-103. doi: 10.1016/j.beem.2014.10.005

21. Liu Z, Mao J, Wu X, Xu H, Wang X, Huang B, et al. Efficacy and outcome predictors of gonadotropin treatment for male congenital hypogonadotropic hypogonadism: a retrospective study of 223 patients. Medicine. (2016) 95:e2867. doi: 10.1097/MD.0000000000 002867

22. Anonymous. Efficacy and safety of highly purified urinary follicle-stimulating hormone with human chorionic gonadotropin for treating men with isolated hypogonadotropic hypogonadism. European Metrodin HP Study Group. Fertil Steril. (1998) 70:256-62. doi: 10.1016/S0015-0282(98)00156-3

23. Bouloux P, Warne DW, Loumaye E, FSH Study Group in Men's Infertility. Efficacy and safety of recombinant human follicle-stimulating hormone in men with isolated hypogonadotropic hypogonadism. Fertil Steril. (2002) 77:270-3. doi: 10.1016/S0015-0282(01)02973-9

24. Sinisi AA, Esposito D, Bellastella G, Maione L, Palumbo V, Gandini L, et al. Efficacy of recombinant human follicle stimulating hormone at low doses in inducing spermatogenesis and fertility in hypogonadotropic hypogonadism. J Endocrinol Invest. (2010) 33:618-23. doi: 10.1007/BF03 346659

25. Nieschlag E, Bouloux PG, Stegmann BJ, Shankar RR, Guan Y, Tzontcheva A, et al. An open-label clinical trial to investigate the efficacy and safety of corifollitropin alfa combined with hCG in adult men with hypogonadotropic hypogonadism. Reprod Biol Endocrinol. (2017) 15:17. doi: 10.1186/s12958-017-0232-y

26. Fraietta R, Zylberstejn DS, Esteves SC. Hypogonadotropic hypogonadism revisited. Clinics. (2013) 68 (Suppl 1):81-8. doi: 10.6061/clinics/2013(Sup01)09

27. Yang L, Zhang SX, Dong Q, Xiong ZB, Li X. Application of hormonal treatment in hypogonadotropic hypogonadism: more than ten years experience. Int Urol Nephrol. (2012) 44:393-9. doi: 10.1007/s11255-011-0065-0

28. Depenbusch M, von Eckardstein S, Simoni M, Nieschlag E. Maintenance of spermatogenesis in hypogonadotropic hypogonadal men with human chorionic gonadotropin alone. Eur J Endocrinol. (2002) 147:617-24. doi: 10.1530/eje.0.1470617

29. Zhang M, Tong G, Liu Y, Mu Y, Weng J, Xue Y, et al. Sequential versus continual purified urinary FSH/hCG in men with idiopathic hypogonadotropic hypogonadism. J Clin Endocrinol Metab. (2015) 100:244955. doi: 10.1210/jc.2014-3802

30. Casarini L, Santi D, Brigante G, Simoni M. Two hormones for one receptor: evolution, biochemistry, actions, and pathophysiology of LH and hCG. Endocr Rev. (2018) 39:549-92. doi: 10.1210/er.2018-00065

31. Schill WB, Jungst D, Unterburger P, Braun S. Combined hMG/hCG treatment in subfertile men with idiopathic normogonadotrophic oligozoospermia. Int $J$ Androl. (1982) 5:467-77. doi: 10.1111/j.1365-2605.1982.tb 00278.x

32. Knuth UA, Honigl W, Bals-Pratsch M, Schleicher G, Nieschlag E. Treatment of severe oligospermia with human chorionic gonadotropin/human menopausal gonadotropin: a placebo-controlled, double blind trial. $J$ Clin Endocrinol Metab. (1987) 65:1081-7. doi: 10.1210/jcem-65-6-1081

33. Kamischke A, Behre HM, Bergmann M, Simoni M, Schafer T, Nieschlag E. Recombinant human follicle stimulating hormone for treatment of male idiopathic infertility: a randomized, double-blind, placebo-controlled, clinical trial. Hum Reprod. (1998) 13:596-603. doi: 10.1093/humrep/13.3.596

34. Simoni M, Santi D, Negri L, Hoffmann I, Muratori M, Baldi E, et al. Treatment with human, recombinant FSH improves sperm DNA fragmentation in idiopathic infertile men depending on the FSH receptor polymorphism p.N680S: a pharmacogenetic study. Hum Reprod. (2016) 31:1960-9. doi: 10.1093/humrep/dew167

35. Casamonti E, Vinci S, Serra E, Fino MG, Brilli S, Lotti F, et al. Short-term FSH treatment and sperm maturation: a prospective study in idiopathic infertile men. Andrology. (2017) 5:414-22. doi: 10.1111/andr.12333

36. Muratori M, Baldi E. Effects of FSH on sperm DNA fragmentation: review of clinical studies and possible mechanisms of action. Front Endocrinol. (2018) 9:734. doi: 10.3389/fendo.2018.00734

37. Santi D, Spaggiari G, Simoni M. Sperm DNA fragmentation index as a promising predictive tool for male infertility diagnosis and treatment management - meta-analyses. Reprod Biomed Online. (2018) 37:315-26. doi: $10.1016 /$ j.rbmo.2018.06.023

38. WHO. WHO Laboratory Manual for the Examination and Processing of Human Semen. Geneva: WHO Press (2010).

39. Attia AM, Abou-Setta AM, Al-Inany HG. Gonadotrophins for idiopathic male factor subfertility. Cochrane Database Syst Rev. (2013) CD005071. doi: 10.1002/14651858.CD005071.pub4

40. Santi D, Granata AR, Simoni M. FSH treatment of male idiopathic infertility improves pregnancy rate: a meta-analysis. Endocr Connect. (2015) 4:R46-58. doi: 10.1530/EC-15-0050

41. Ding YM, Zhang XJ, Li JP, Chen SS, Zhang RT, Tan WL, et al. Treatment of idiopathic oligozoospermia with recombinant human follicle-stimulating hormone: a prospective, randomized, double-blind, placebo-controlled clinical study in Chinese population. Clin Endocrinol. (2015) 83:866-71. doi: $10.1111 /$ cen. 12770

42. Behre HM, Greb RR, Mempel A, Sonntag B, Kiesel L, Kaltwasser $\mathrm{P}$, et al. Significance of a common single nucleotide polymorphism in exon 10 of the follicle-stimulating hormone (FSH) receptor gene for the ovarian response to FSH: a pharmacogenetic approach to controlled ovarian hyperstimulation. Pharmacogenet Genomics. (2005) 15:451-6. doi: 10.1097/01.fpc.0000167330.92786.5e

43. Ferlin A, Vinanzi C, Selice R, Garolla A, Frigo AC, Foresta C. Toward a pharmacogenetic approach to male infertility: polymorphism of folliclestimulating hormone beta-subunit promoter. Fertil Steril. (2011) 96:13441349.e1342. doi: 10.1016/j.fertnstert.2011.09.034

44. Selice R, Ferlin A, Garolla A, Caretta N, Foresta C. Effects of endogenous FSH on normal human spermatogenesis in adults. Int J Androl. (2011) 34(6 Pt 2):e511-7. doi: 10.1111/j.1365-2605.2010.01134.x

45. Schubert M, Pérez Lanuza L, Gromoll J. Pharmacogenetics of FSH action in the male. Front Endocrinol. (2019) 10:47. doi: 10.3389/fendo.2019.00047

46. Barbotin AL, Ballot C, Sigala J, Leroy M, Rigot JM, Dewailly D, et al. Pregnancy after intracytoplasmic sperm injection following extended sperm preparation and hormone therapy in an azoospermic man with maturation arrest and microlithiasis: a case report and literature review. Andrologia. (2017) 49:e12665. doi: 10.1111/and.12665

47. Cocci A, Cito G, Russo GI, Falcone M, Capece M, Timpano M, et al. Effectiveness of highly purified urofollitropin treatment in patients with 
idiopathic azoospermia before testicular sperm extraction. Urologia. (2018) 85:19-21. doi: 10.5301/uj.5000253

48. Laursen RJ, Elbaek HO, Povlsen BB, Lykkegaard J, Jensen KBS, Esteves SC, et al. Hormonal stimulation of spermatogenesis: a new way to treat the infertile male with non-obstructive azoospermia? Int Urol Nephrol. (2019) 51:453-6. doi: 10.1007/s11255-01902091-8

49. Bundesärztekammer. Richtlinie zur Entnahme und Übertragung von menschlichen Keimzellen im Rahmen der assistierten Reproduktion. Deutsches Ärzteblatt. (2018) A1-A22. doi: 10.3238/arztebl.2018.Rili_ assReproduktion_2018
Conflict of Interest Statement: The author declares that the research was conducted in the absence of any commercial or financial relationships that could be construed as a potential conflict of interest.

Copyright (c) 2019 Behre. This is an open-access article distributed under the terms of the Creative Commons Attribution License (CC BY). The use, distribution or reproduction in other forums is permitted, provided the original author(s) and the copyright owner(s) are credited and that the original publication in this journal is cited, in accordance with accepted academic practice. No use, distribution or reproduction is permitted which does not comply with these terms. 